\title{
Cell Culture and Trapping of Yeast Protoplasts Using Au Thin-Film Dielectrophoresis Chip
}

\author{
Kyohei Nishimoto \\ Department of Science and Engineering \\ Ritsumeikan University \\ Japan
}

\author{
Keishu Aritoshi \\ Department of Science and Engineering \\ Ritsumeikan University \\ Japan
}

\begin{abstract}
Dielectrophoresis (DEP) force will arise when an inhomogeneous AC electric field with sinusoidal wave form is applied to micro electrodes. The DEP is able to distinguish between viable and non-viable biological cells by their movement through a non-uniform electric field. The viable cells can be used for analytic chemistry, cell culture or fusion. The aim of this research is yeast cell culture after distinction of viable and nonviable cells on Au thin-film DEP chip. We fabricated a planar double pole electrode for DEP using Au thin-film and a box cutter. This fabrication method is low cost and simpler than the previous existing methods. We observed cell culture under the terms of DEP (1Vpp-5MHz) after distinction between viable and non-viable yeast cells. The Au thin-film DEP chip could obtain viable cells which were trapped at the micro electrodes. The daughter cell became as big as the mature cells after about 50 minutes of observation. In other experiments, we confirmed whether the Au thin-film DEP chip can trap yeast protoplasts or not. When we applied $4 \mathrm{Vpp}$ and over $40 \mathrm{kHz}$, the yeast protoplasts were trapped at the micro electrode. This experimental result is very important for performing fusion of cells. We confirmed usefulness and possibility of Au thin-film DEP chip through these experiments.
\end{abstract}

Keywords-dielectrophoresis; Au thin-film; yeast cell; protoplast; fusion and cell culture

\section{INTRODUCTION}

The determination of cell viability is very important for culture and fusion [1]. Generally, the distinction methods of viable and non-viable cells are colony-forming assay, fluorochrome and methylene blue stain and so on. These methods have various issues such as long-term culture and cell invasion. On the other hand, dielectrophoresis (DEP) doesn't need dye test for characterization. DEP can obtain the result immediately and distinguish between viable and non-viable cells by their movement through a non-uniform electric field [2]. In medical field, it may be possible to use this method to test whether the cell is normal or not with little amount of sample. In general, a micro electrode of DEP is fabricated by photolithography or laser ablation and so on [3, 4]. These methods are costly and need complex processes. Therefore, we suggested a simplified fabrication method of Au thin-film DEP chip [5].

\author{
Kozo Taguchi \\ Department of Science and Engineering \\ Ritsumeikan University \\ Japan
}

In this paper, we confirmed the usefulness of the Au thinfilm DEP chip through two experiments. The first experiment is yeast cell culture after distinction between viable and nonviable cells. The feature of this research is that it is possible to observe cell culture after distinction of cell viability on the single chip. The second experiment is trapping of yeast protoplasts on the $\mathrm{Au}$ thin-film chip. Trapping of yeast protoplasts is a beneficial process for cell fusion.

\section{METHODS AND MATERIALS}

The micro electrode of the Au thin-film DEP chip was fabricated by a box cutter and coating Au thin-film on a glass slide. Fig. 1 shows the first step of the Au thin-film DEP chip fabrication processes. In order to make micro electrode shape, we put an adhesive tape on the glass slide. The adhesive tape has a hole of $15 \times 20 \mathrm{~mm}$. The Au thin-film was coated by deposition with an ion coater (IB-3 Eiko). Then, we cut the surface of the Au thin-film by a box cutter (SB10BS OLFA). Fig. 2 shows double pole electrode. The gap width is about $25 \mu \mathrm{m}$. In case of the planar double pole electrode, electric field gradient are shown in fig. 3. The force acting on the strong electric field area is called positive-DEP. On the other hand, the force acting on weak electric field area is called negative-DEP.
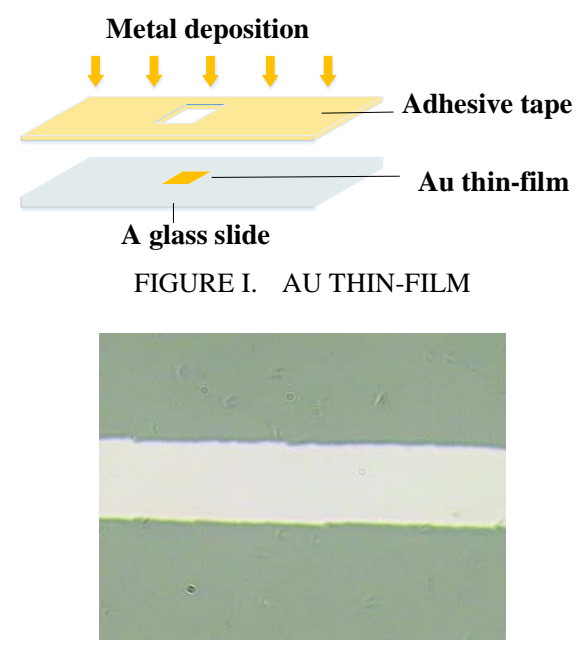

FIGURE II. DOUBLE POLE ELECTRODE. 


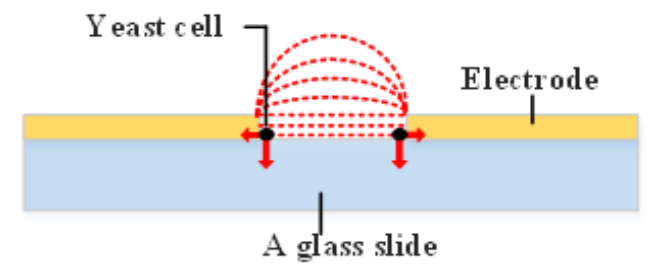

FIGURE III. IMAGE OF ELECTRIC FIELD GRADIENT

We prepared viable, non-viable yeast cells and yeast protoplasts as specimens. Non-viable cells were obtained by a heat treatment during 10 minutes at $80^{\circ} \mathrm{C}$. Fig. 4-a shows $\mathrm{Au}$ thin-film DEP chip. We made a pool by silicone rubber to observe cell culture on the electrode (fig. 4-b). This DEP chip fabrication method is low cost and simpler than the previous existing methods.

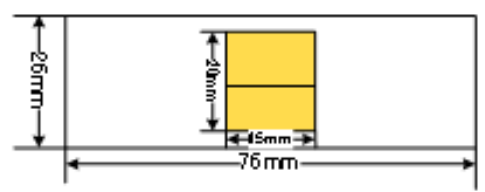

(4-a)

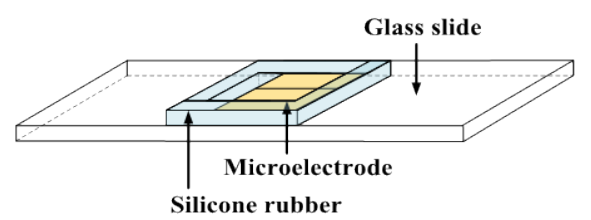

(4-b)

FIGURE IV.(4-a)AU THIN-FILM DEP CHIP.(4-b)AU THIN-FILM DEP CHIP FOR CELL CULTURE.

\section{USEFULNESS OF AU THIN-FILM DEP CHIP AND CONDITIONS}

\section{A. The determination of Cell Viability Using Au Thin- Film DEP Chip}

Viable and non-viable cells have different frequency dependence for different permittivity and conductivity. DEP can shift to positive-DEP or negative-DEP depending on the frequency used. We applied AC electric field (sinusoidal wave) to micro electrodes. Viable cells show negative-DEP when frequency is lower than $300 \mathrm{kHz}$ and positive-DEP when frequency is higher than $300 \mathrm{kHz}$ in water. Non-viable cells still show negative-DEP from $10 \mathrm{kHz}$ to $15 \mathrm{MHz}$ in water. By using different permittivity and conductivity one can easily distinguish viable and non-viable cells. Fig. 5 shows the distinction of viable and non-viable yeast cells in water. The blue particles are non-viable cells that were dyed by using a methylene blue in order to visualize the movement of cells.
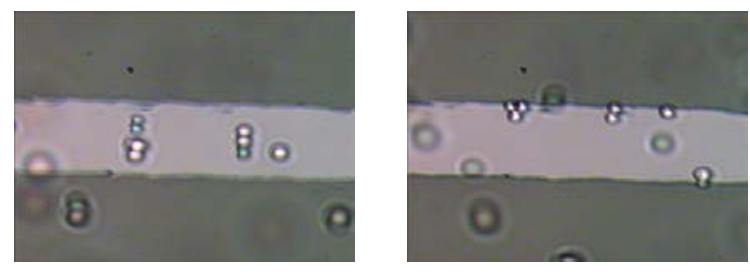

FIGURE V. DISTINCTION OF VIABLE AND NON-VIABLE CELLS IN WATER (50×).
Fig. 5-a shows the experiment before applying frequency and voltage. In Fig. 5-b, we applied AC electric field with voltage and frequency, $\mathrm{Vpp}=4, \mathrm{f}=15 \mathrm{MHz}$. Only viable cells were attracted to the micro electrode by the effect of positiveDEP. On the other hand, non-viable cells were levitated by the effect of negative-DEP. In short, we could distinguish between viable and non-viable cells.

\section{B. Yeast Cell Culture Using Au Thin-film DEP Chip}

We observed yeast cells culture through DEP after distinction between viable and non-viable yeast cells by positive and negative-DEP forces. YPD solution is essential to cell culture. YPD solution is the compounds of yeast extract, glucose and peptone. We added YPD solution to water. Table. 1 shows frequency condition of negative- and positive-DEP applied to viable and non-viable cells suspended in different solutions. Due to the change of solution, viable cells moved to negative-DEP when frequency is lower than $1.7 \mathrm{MHz}$. When frequency is higher than $1.7 \mathrm{MHz}$, the viable cells moved to positive-DEP. Non-viable cells still show negative-DEP from $10 \mathrm{kHz}$ to $15 \mathrm{MHz}$. To distinguish them, we applied AC electric field with $1 \mathrm{Vpp}$ voltage and frequency over $1.7 \mathrm{MHz}$ to the micro electrode. In case of viable cells, they were moved to the micro electrode by the effect of positive-DEP. We confirmed that the cells are viable cells in this process.

TABLEI. Frequency Condition OF NEgative- AND Positive-DeP ApPlied To VIABle AND Non-VIable CELls SusPended IN DifFERENT SOLUTIONS

\begin{tabular}{|c|c|c|c|}
\hline Solutions & Cell types & Negative-DEP & $\begin{array}{c}\text { Positive- } \\
\text { DEP }\end{array}$ \\
\hline \multirow{2}{*}{ Water } & Viable cells & $<0.3 \mathrm{MHz}$ & $>0.3 \mathrm{MHz}$ \\
\cline { 2 - 4 } & Non-viable cells & $10 \mathrm{kHz} 15 \mathrm{MHz}$ & \\
\hline $\begin{array}{c}\text { YPD solution } \\
\text { water }\end{array}$ & Viable cells & $<1.7 \mathrm{MHz}$ & $>1.7 \mathrm{MHz}$ \\
\cline { 2 - 4 } & Non-viable cells & $10 \mathrm{kHz} 15 \mathrm{MHz}$ & \\
\hline
\end{tabular}

We carried out the determination of cell viability and the cell culture experiment by using single Au thin-film DEP chip. We applied AC electric field with voltage and frequency, $\mathrm{Vpp}=1, \mathrm{f}=5 \mathrm{MHz}$. The viable cells were trapped to the micro electrode by the effect of positive-DEP. We observed the viable cells for 1 hour with the same voltage and frequency. During the experiment, we recorded and observed the budding yeast cells on a VTR with a CCD camera. Fig. 6 shows the experimental setup for distinction of viable and non-viable cells and cell culture. Fig. 7 shows the growth of cell culture.

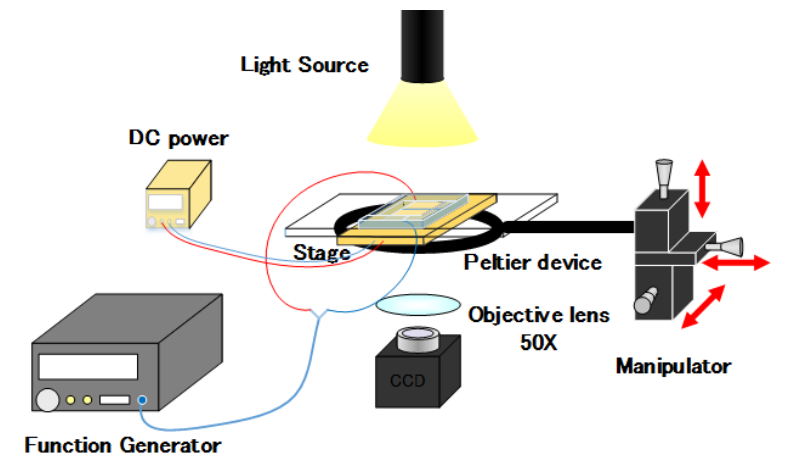

FIGURE VI. THE EXPERIMENTAL SETUP FOR CELL CULTURE 
The Au thin-film DEP chip of fig. 4-b was equipped on the stage of the experimental setup. During the cell culture, we used a peltier device to keep the cell culture solution temperature at $28^{\circ} \mathrm{C}$.
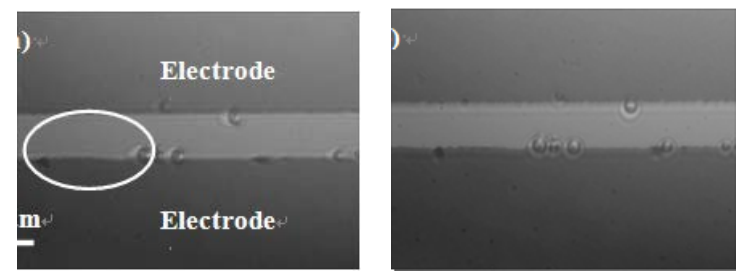

(7-a) Begin observing (7-b) 20min later
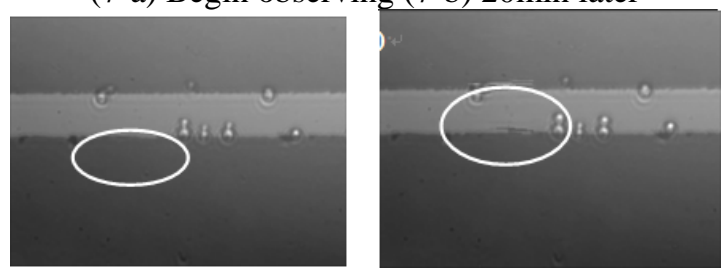

(7-c) 40min later (7-d) 50min later

FIGURE VII. YEAST CELL CULTURE (50×)

\section{C. $\quad$ Trapping of Yeast Protoplasts Using Au Thin-film DEP Chip}

We confirmed whether the chip can trap yeast protoplasts or not. The solution of $1 \mathrm{M}$ sorbitol was used as isotonic solution of Saccharomyces cerevisiae [6]. S. cerevisiae have a cell wall. When the cell wall is removed, it is called protoplast. Protoplasts are essential to fuse cells. Protoplasts are surrounded by only a thin membrane. They can be damaged by a little bit of stimulus because it is very weak. The protoplasts can dissolve and burst due to the tension between internal pressure and external pressure. In hypertonic solution, the protoplasts shrivel up because the osmotic pressure outside the cell is higher than inside of the cell (fig. 8-a). The protoplasts burst by expanding as a result of inner osmotic pressure in hypotonic solution (fig. 8-b). In isotonic solution, there is no difference in pressure inside and outside of a cell for the equal strength of a solution (fig. 8-c).

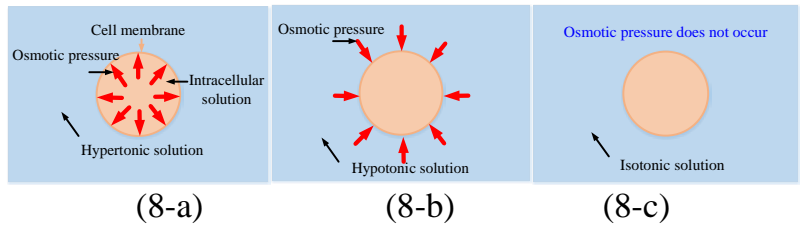

FIGURE VIII. (8-a)CELL IN HYPERTONIC SOLUTION(8-b) CELL IN HYPOTONIC SOLUTION.FIGURE (8-c)CELL IN ISOTONIC SOLUTION.

Fig. 9 shows the experimental result of protoplasts trapping at the planar double pole electrode. Protoplasts showed negative-DEP in $1 \mathrm{M}$ sorbitol when frequency was $10 \mathrm{kHz}$. When frequency was higher than $40 \mathrm{kHz}$, the protoplasts switched to positive-DEP. We checked whether the trapping cell was a protoplast or not by adding water in order to create a hypotonic solution. From previous results, positive-DEP force is about 10 times or more strong than negative-DEP force [5]. We adjusted the frequency to $500 \mathrm{kHz}$. The cell exploded because of hypotonic solution in fig. 9-c and 9-d. Therefore, this shows that the cell was a protoplast. Based on this result, it can be said that the yeast protoplasts can be trapped by the $\mathrm{Au}$ thin-film DEP chip.
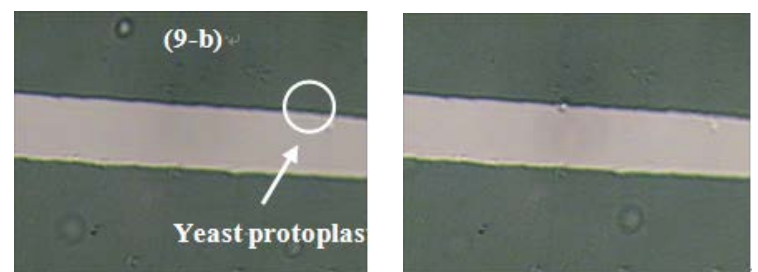

(9-a) Initial stage. (9-b) We applied AC electric field with voltage and frequency $(\mathrm{Vpp}=4, \mathrm{f}=40 \mathrm{kHz})$. The cell was trapped at the micro electrode. Frequency was adjusted to $500 \mathrm{kHz}$ with the same voltage.
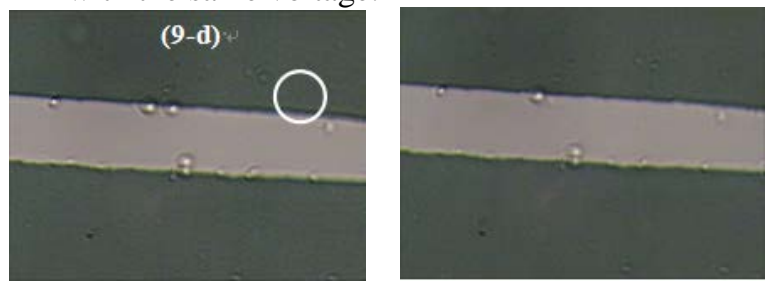

(9-c) We add water in order to create a hypotonic solution. (9-d) The cell exploded by this process.

FIGURE IX. RAPPING OF YEAST PROTOPLASTS ON A PLANAR DOUBLE POLE ELECTRODE.

\section{RESULTS AND DISCUSSION}

As shown in fig. 7, the daughter cell grew in size as time advances. After 50 minutes of observation, the daughter cell became as big as the others. We were able to observe yeast cell culture under DEP (1Vpp-5MHz) after distinction between viable and non-viable cells. In addition, we did other experiments to investigate the trapping of yeast protoplasts on the $\mathrm{Au}$ thin-film DEP chip. The experimental results were shown in fig. 9. In the case of a planar double pole electrode, the protoplasts were trapped to micro electrode by positiveDEP. Trapping frequency of cells is different by solution. However, there is a clear trend of frequency dependence.

\section{CONCLUSION}

The Au thin-film DEP chip was fabricated by simplified method. The Au thin-film DEP chip could distinguish between viable and non-viable cells and obtain viable cells which were trapped at the micro electrode by the effect of positive-DEP. The cells trapped by DEP could be used for cell culture. Through this cell culture experiment, we were able to confirm usefulness and possibility of the Au thin-film DEP chip. We succeeded the determination of cell viability and cell culture on the single $\mathrm{Au}$ thin-film DEP chip. In addition, we confirmed that yeast protoplasts can also be trapped by Au thin-film DEP chip. This result shows possibility to increase the rate of the cell fusion.

\section{ACKNOWLEDGEMENT}

The authors would like to thank Prof.Wakayama. The yeast cells were supplied from Enzyme Technology Lab of Ritsumeikan Univ. 


\section{REFERENCE}

[1] Y. Mizuta \& K. Taguchi., Efficient PEG fusion Combined Optical Tweezers and Dielectrophoresis. Applied Mechanics and Materials, Vol.595 pp 61-64, 2014.

[2] C.Wei \& C.Liang., a microfluidic system with non-embedded tilting inter-castellated electrode for dielectrophoretic separation. Journal of the Chinese Institute of Engineers, Vol. 33, No. 1, pp.15-23, 2010.

[3] I. Ikeda, K. Matsumaru \& H. Watari., Dielectrophoresis of mictoparticles with planar and capillary quadrupole electrodes. world Automation Congress, 2010 TSI Press.

[4] A. L. Clow, P. T. Gaynor \& B. Oback., A Micropit for Biological Cell Positioning. IEEE International Conference on Control and Automation Christchurch, New Zealand, December 9-11, 2009.

[5] K. Nishimoto \& K.Taguchi., A Simplified Fabrication Method of Dielectrophoresis Chip Using Au thin-film and Box Cutter. Advanced Materials Research Vol. 909 pp 58-62, 2014.

[6] S. Koseko, Y. Yoshinori, M. Hisamatsu \& T. Yamada., Studies on Cell Fusion of Soy-Sauce Yeast: Part2 Preparation Condition of Protoplast and Electoroporation Condition. The bulletin of the Faculty of Bioresources, Mie University, pp.79-85, 3,1990. 